\title{
EFFICACY OF FORCED-AIR AND INHALATION REWARMING USING A HUMAN MODEL FOR SEVERE HYPOTHERMIA
}

\author{
M.S.L. Goheen, M.B. Ducharmet, G.P. Kenny, C.E. Johnston, \\ G.K. Bristow, G.G. Giesbrecht \\ University of Manitoba, Laboratory for Exercise and Environmental Medicine, \\ Winnipeg, Manitoba; Canada, R3T 2N2; \\ † Defence and Civil Institute of Environmental Medicine, \\ North York, Ontario, Canada, M3M 3B9.
}

\section{INTRODUCTION}

To date, laboratory research on field treatment for hypothermia has been limited to mild hypothermic situations [i.e., core temperature $\left(\mathrm{T}_{\infty}\right)>33.5^{\circ} \mathrm{C}$ ] in which subjects shiver vigorously. Shivering thermogenesis is a powerful heat source for endogenous rewarming. Because exogenous external application of moderate sources of heat [i.e., electrical or portable heat packs, body-to-body contact, forcedair warming systems $(100 \mathrm{~W})$, and circulating warm water blankets or vests] warms the skin and inhibits shivering heat production, these methods provide little advantage when vigorous shivering is present (1).

However, exogenous heat is likely crucial for victims of severe hypothermia in which shivering is impaired or absent. In such cases, invasive exogenous internal rewarming techniques (i.e., peritoneal lavage and extracorporeal warming) are preferred to stabilize and raise $T_{c o}$. In the field however, these techniques are impractical, whereas non-invasive exogenous heat donation is practical and would also likely benefit the patient.

The efficacy of non-invasive heating techniques on non-shivering hypothermic subjects has not been previously investigated. For obvious ethical reasons, it is impossible to study different rewarming treatments at $\mathrm{T}_{\circ 0}<30{ }^{\circ} \mathrm{C}$ where the shivering response is suppressed. However, we have recently developed a human model for severe hypothermia (2) in which we administered meperidine to inhibit shivering in mildly hypothermic subjects. Under these conditions $\mathrm{T}_{\mathrm{co}}$ afterdrop averages $1.4{ }^{\circ} \mathrm{C}$ and reaches values as high as $2.5^{\circ} \mathrm{C}$ (compared to $\sim 0.3{ }^{\circ} \mathrm{C}$ during shivering). Without the endogenous heat production of shivering $T_{c o}$ remains at or near its lowest point for the entire length of the rewarming period (i.e., $150 \mathrm{~min}$ ). This model could be used to study the application of non-invasive exogenous heat (by external and internal methods) to non-shivering hypothermic subjects.

Therefore we evaluated $T_{c o}$ recovery in field-like conditions $\left(T_{a}=-20^{\circ} \mathrm{C}\right)(3)$ while employing: 1) Endogenous Rewarming (no exogenous heat donation) (Control); 2) Inhalation Rewarming (Res-Q-Air, HT 1000 Inhalation Delivery System); and 3) Forced-Air Warming with a newly developed system that provides a high amount of convective heat transfer (200-280 W). 


\section{METHODS}

Six men and 2 women $[30 \pm 5.2 \mathrm{yrs}(\mathrm{SD}), 74.3 \pm 6.9 \mathrm{Kg}, 177.2 \pm 8.0 \mathrm{~cm}]$ of average fitness participated in the study. All subjects underwent medical screening and gave written informed consent.

Core body temperature was monitored at the esophagus $\left(T_{e s}\right)$. Skin temperature and heat flux were monitored at 12 sites and the area-weighted means were calculated. Heart rate and blood pressure were monitored continuously. Oxygen consumption $\left(\mathrm{VO}_{2}\right)$ was determined by an open circuit method. Intravenous access was obtained in the right forearm or hand using a 20-gauge intravenous catheter for the purpose of administering meperidine and/or saline $(0.9 \%$ sodium chloride).

The new Forced-Air Warming System consisted of a mobile insulated wooden box (1.6 m long $\times 0.725 \mathrm{~m}$ wide by $0.33 \mathrm{~m}$ high) with a nylon webbing stretcher (2.14 $\mathrm{m}$ long) supported on top. With the subject lying on the stretcher, a wire frame (curved side-to-side) was placed over the subject. The rostral portion of the box was hollow and contained two electric heaters and 6 circulating fans below the webbed stretcher. Two more heaters and 3 fans were contained in an enclosed section on top of the wire frame just above the subject's chest. A down sleeping bag was then placed over the wire frame. The head of the subject (which was exposed to ambient conditions) was covered with a down hood. The system configuration allowed exposure to air of all anterior skin surfaces and posterior skin surfaces from mid thigh to the shoulders. When the heaters were used, the circulating fans were activated and the heaters were thermostatically controlled to maintain ambient temperature within the box at approximately $46-48^{\circ} \mathrm{C}$.

Each subject was cooled on three occasions separated by at least 3 days. Trials were conducted at the same time of day. Baseline data were collected over $10 \mathrm{~min}$ at an ambient temperature $\left(\mathrm{T}_{\mathrm{a}}\right)$ of $22^{\circ} \mathrm{C}$. Prior to immersion the subject was dressed with a thin plastic body suit [this suit ensured that the subject was dry following water immersion] which minimized evaporative heat loss during rewarming without the time consuming and mechanically stimulating process of towel drying. Using a mechanical hoist, the subject was transferred and immersed to the clavicles in $22{ }^{\circ} \mathrm{C}$ water. Water was then rapidly cooled to $9^{\circ} \mathrm{C}$ within $10 \mathrm{~min}$ by the addition of ice. After $15 \mathrm{~min}$ of immersion, the subject was infused with $1.5 \mathrm{mgkg}^{-1}$ of meperidine (diluted in $10 \mathrm{ml}$ of saline) injected in five $2 \mathrm{ml}$ aliquots in successive $2 \mathrm{~min}$ periods (total immersion time $=25 \mathrm{~min}$ ). The subject was then hoisted out of the water, and the body suit was removed. A pulse oximeter was placed on the middle finger to monitor arterial oxygen saturation.

In order to control for external variables, each subject was placed in the rewarming box [and fitted with long thinsulate insulated boots (up to the knee) and mitts (up to the elbows)] for each of the 3 treatment conditions. The box was then transferred to a temperature controlled chamber at $T_{a}$ of $-20^{\circ} \mathrm{C}$ where either: 1 ) the 
subject breathed ambient air $\left(-20^{\circ} \mathrm{C}\right)$ with no exogenous heat donation (Control); 2) the subject breathed warm humidified air $\left(43^{\circ} \mathrm{C}\right)$ (Inhalation Rewarming); or 3) the subject breathed ambient air $\left(-20^{\circ} \mathrm{C}\right)$ with the rewarming box heating system activated (Forced-Air Warming). During spontaneous rewarming (Control), each subject required supplemental doses of mepiridine to maintain shivering inhibition (to a maximum cumulative dose of $2.5 \mathrm{mg} \mathrm{kg}^{-1}$ ). Therefore the Control condition occurred first for all subjects. Thereafter, treatment order followed a balanced design with the meperidine dossing šchedüle following that established during Control. Rewarming duration was continued for a maximum of 150 min or until $T_{e s}$ reached $36.8^{\circ} \mathrm{C}$.

\section{RESULTS}

\section{Cooling phase}

Baseline $\mathrm{T}_{\mathrm{es}}\left(\sim 37.1^{\circ} \mathrm{C}\right), \mathrm{T}_{\mathrm{Bk}}\left(\sim 31.5^{\circ} \mathrm{C}\right)$ and $\mathrm{Vo}_{2}\left(\sim 329 \mathrm{mi}^{-1} \mathrm{~min}^{-1}\right)$ were similar for each condition. Upon immersion $\mathrm{Vo}_{2}$ increased to $\sim 569 \mathrm{ml}^{-} \mathrm{min}^{-1}$. Following the five $2 \mathrm{~min}$ injections of meperidine injection, $V o_{2}$ dropped to $\sim 361 \mathrm{mlmin}^{-1} . \mathrm{T}_{\mathrm{es}}$ at end-immersion $(25 \mathrm{~min})$ was $36.71 \pm 0.39^{\circ} \mathrm{C}, 36.76 \pm 0.39^{\circ} \mathrm{C}, 36.68 \pm 0.39^{\circ} \mathrm{C}$ in Control, Inhalation Rewarming and Forced-Air Warming conditions respectively.

\section{Rewarming phase}

$\mathrm{T}_{\mathrm{es}}$ continued to drop in all three conditions during the preparatory phase for rewarming (i.e., suit removal and transfer to rewarming box). A significantly larger afterdrop was measured for Control $\left(1.40 \pm 0.22^{\circ} \mathrm{C}\right)$ and Inlalation Rewarming $\left(1.22 \pm 0.45^{\circ} \mathrm{C}\right)$ conditions than for Forced-Air Warming $\left(0.85 \pm 0.39^{\circ} \mathrm{C}\right)$ [Table 1, $(p<0.05)]$. This corresponded to a shorter time to reach the nadir in $\mathrm{T}_{\text {es }}$ during Forced-Air Warming $(13.1 \pm 5.8 \mathrm{~min})$ than for Control $(77.9 \pm 32.6 \mathrm{~min})$ and Inhalation Rewarming ( $75.8 \pm 27.9 \mathrm{~min})(\mathrm{p}<0.05)$. During Control and Inhalation Rewarming, $\mathrm{T}_{\mathrm{es}}$ remained near nadir levels with rewarming rate of only $0.41 \pm 0.39$ ${ }^{\circ} \mathrm{C} \cdot h r^{-1}$ and $0.23 \pm 0.15^{\circ} \mathrm{C} \cdot \mathrm{hr}^{-1}$ respectively, compared to $2.40 \pm 0.99{ }^{\circ} \mathrm{C} \cdot \mathrm{hr}^{-1}$ for Forced-Air Warming $(\mathrm{p}<0.05)$.

Total heat loss throughout Control and Inhalation Rewarming was about $40 \mathrm{~W}$. In comparison Forced-Air Warming provided a total heat gain of between 200 and $280 \mathrm{~W}$. After $30 \mathrm{~min}$ of rewarming, $\mathrm{T}_{\mathrm{Bk}}$ during Forced-Air Warming was $\sim 35.5^{\circ} \mathrm{C}$ $\left(4.5^{\circ} \mathrm{C}\right.$ above baseline) while $\mathrm{T}_{\mathrm{sk}}$ for Control $\left(27.0^{\circ} \mathrm{C}\right)$ and Inhalation Rewarming $\left(\sim 28.3^{\circ} \mathrm{C}\right)$ were $4.5^{\circ} \mathrm{C}$ and $3.2{ }^{\circ} \mathrm{C}$ below baseline respectively $(\mathrm{p}<0.0001)$. During the rewarming period, $\mathrm{Vo}_{2}$ decreased to levels not significantly different from baseline values for all 3 conditions. 
Table 1. Rewarming parameters for the three experimental conditions.

\begin{tabular}{lccc} 
Condition & $\begin{array}{c}\text { Afterdrop } \\
\left({ }^{\circ} \mathbf{C}\right)\end{array}$ & $\begin{array}{c}\text { Time to nadir } \\
\text { (min) }\end{array}$ & $\begin{array}{c}\text { Rate of rewarming } \\
\left({ }^{\circ} \mathbf{C} \mathbf{h r}^{-1}\right)\end{array}$ \\
\hline Control & $1.40(0.2)$ & $77.9(32.6)$ & $0.41(0.4)$ \\
Inhalation Rewarming & $1.22(0.5)$ & $75.8(27.9)$ & $0.23(0.2)$ \\
Forced-Air Warming & $0.85(0.4)^{*}$ & $13.1(5.8)^{*}$ & $2.40(1.0)^{*}$
\end{tabular}

(Mean $\pm \mathrm{SD}, *$ indicates significant difference from Inhalation Rewarming and Control)

\section{CONCLUSION}

The small absolute decrease in $T_{c o}$ was dictated by the maximal cooling for which clinical doses of meperidine could still effectively inhibit shivering. In our non-shivering mildly hypothermic subjects, $T_{e s}$ did not increase appreciably even after $150 \mathrm{~min}$ of inhalation rewarming or spontaneous rewarming. However, when hypothermic subjects were placed in a forced-air warming box the rate of rewarming was impressive. This latter method holds considerable promise for use in field situations. Finally, this new human model for severe hypothermia will allow the study of many methods, which have previously been affected by the complicating factor of shivering thermogenesis.

\section{REFERENCES}

1. Giesbrecht, G.G., Bristow, G.K., Uin, A., Ready, A.E., Jones, R.A. 1987, Effectiveness of three field treatments for induced mild $\left(33.0^{\circ} \mathrm{C}\right)$ hypothermia. Journal of Applied Physiology, 64, 2375-2379.

2. Giesbrecht, G.G., Goheen, M.S.L., Johnston, C.E., Bristow, G.K., Hayward, J.S. 1995, An experimental model for severe hypothermia in humans (abstract). FASEB Journal, 9, A646.

3. Mekjavic, I.B., Eiken, O. 1995, Inhalation rewarming from hypothermia: an evaluation in $-20^{\circ} \mathrm{C}$ simulated field conditions. Aviation, Space and Environmental Medicine, 66, 424-429.

Support: Dept. Nat. Defence (D.C.I.E.M.), NSERC, MHRC and Augustine Med. Inc. 